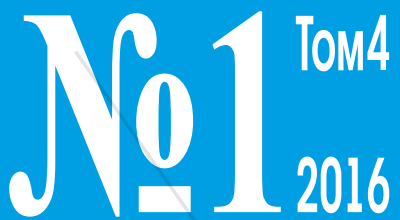

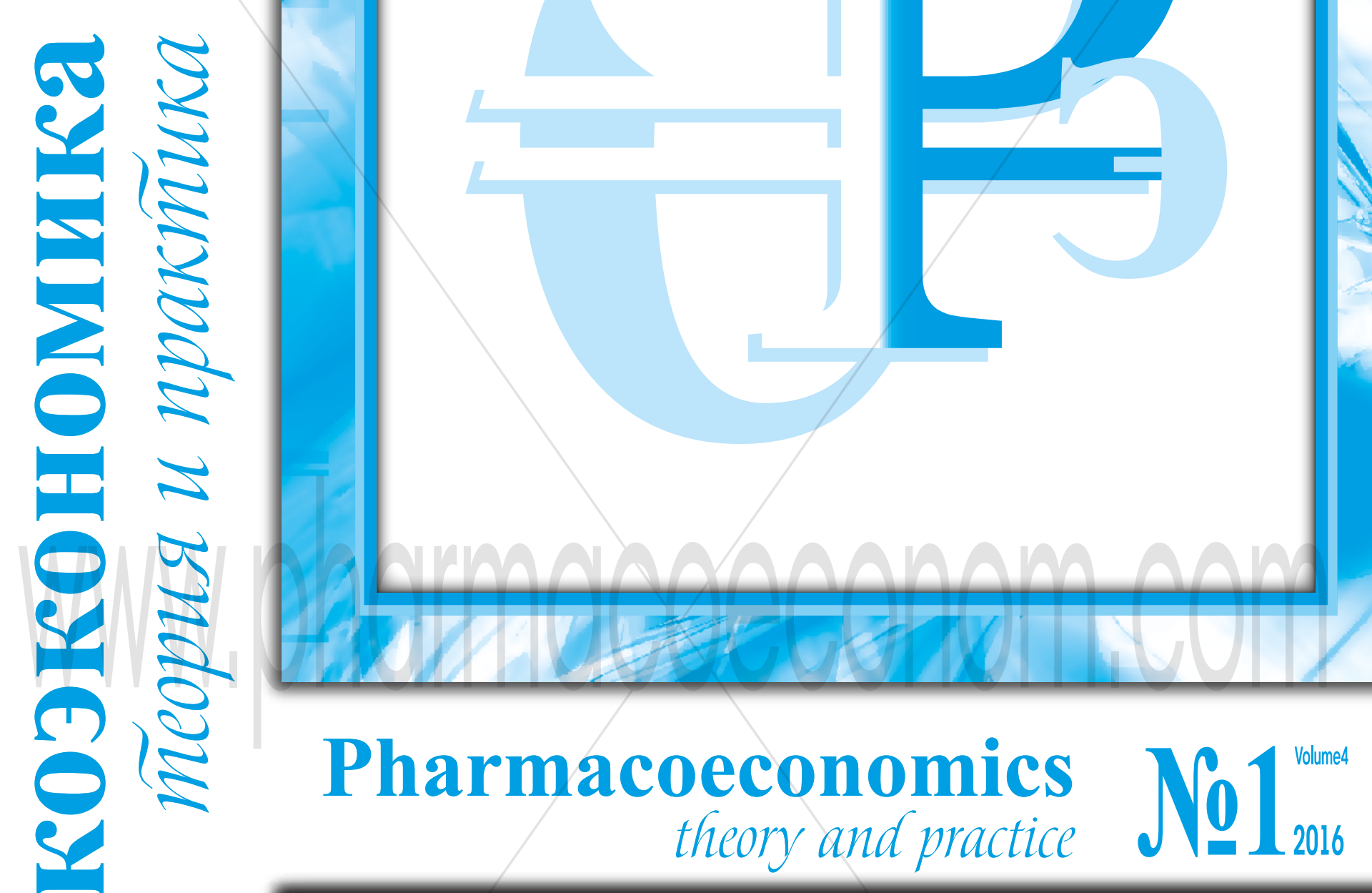

$\square$ МЕТОДОЛОГИЧЕСКИЕ ОСНОВЫ ФАРМАКОЭКОНОМИЧЕСКОГО МОДЕЛИРОВАНИЯ

$\square$ РЕЗУЛЬТАТЫ РОССИЙСКИХ ФАРМАКОЭКОНОМИЧЕСКИХ ИССЛЕДОВАНИЙ

口 МАТЕРИАЛЫ Х НАЦИОНАЛЬНОГО КОНГРЕССА С МЕЖДУНАРОДНЫМ УЧАСТИЕМ «РАЗВИТИЕ ФАРМАКОЭКОНОМИКИ И ФАРМАКОЭПИДЕМИОЛОГИИ В РОССИЙСКОЙ ФЕДЕРАЦИИ» 4-5 апреля 2016 г., г. Нижний Новгород 


\title{
ОЦЕНКА ЗАТРАТ НА КОРРЕКЦИЮ ОСЛОЖНЕНИЙ ХРОНИЧЕСКОЙ БОЛЕЗНИ ПОЧЕК И ЗАМЕСТИТЕЛЬНОЙ ПОЧЕЧНОЙ ТЕРАПИИ У ПАЦИЕНТОВ С ТЕРМИНАЛЬНОЙ ПОЧЕЧНОЙ НЕДОСТАТОЧНОСТЬЮ
}

\author{
COST ESTIMATES FOR THE CORRECTION COMPLICATIONS OF CHRONIC \\ KIDNEY DISEASE AND RENAL REPLACEMENT THERAPY IN PATIENTS \\ WITH END-STAGE RENAL FAILURE
}

\author{
Абдрамитова Г.Т. \\ Abdrashitova G.T.
}

ГБОУ ВПО «Первый МГМУ им. И.М. Сеченова»

State Budgetary Educational Institution of Higher Professional Education "I.M. Sechenov First Moscow State Medical University" of the Ministry of Heath of the Russian Federation, Moscow

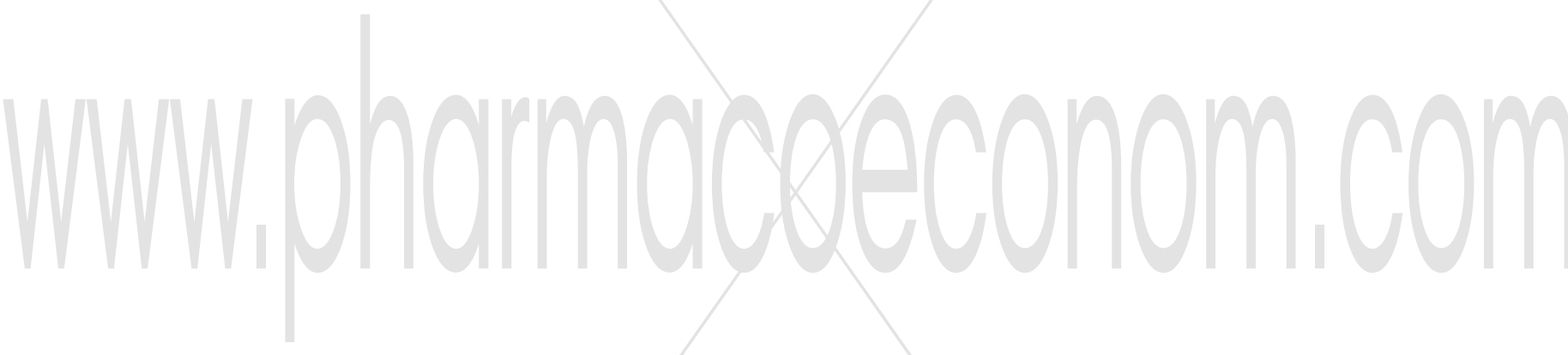

Ключевые слова: хроническая болезнь почек, осложнения, заместительная почечная терапия, анализ затрат, терминальная стадия, гемодиализ, перитонеальный диализ.

Введение: рассматривая особенности проведения фармакоэкономических исследований в области нефрологии, в первую очередь важно учитывать клинические и терапевтические аспекты заболевания, к которым относятся характерная картина развития стадий заболевания, наиболее значимые осложнения и подходы к терапии данной нозологии.

Цель исследования: провести анализ затрат, связанных с коррекцией осложнений, возникающих на фоне хронической болезни почек (ХБП) и непосредственно при заместительной почечной терапии (ЗПТ) у пациентов с терминальной почечной недостаточностью (ТПН).

Материалы и методы: информационный поиск в открытых источниках, анализ прямых затрат.

Результаты: в анализе затрат на коррекцию осложнений ХБП подробно рассматривались наиболее часто встречающиеся осложнения такие как анемия, вторичный гиперпаратиреоз (ВГПТ) и различные сердечно-сосудистые заболевания (СС3), такие как инфаркт миокарда, артериальная гипертензия, инсульт и стенокардия. К осложнениям ЗПТ были отнесены затраты на лечение перитонитов на фоне проведения перитонеального диализа (ПД) и затраты на лечение сепсиса при назначении пациентам как гемодиализа (ГД), так и ПД. Информация о частотах возникновения анемии и ВГПТ у пациентов с ТПН была взята из отчетов Российского диализного общества (РДО), в то время как данные о частоте госпитализаций по причине ССЗ в отечественных источниках обнаружены не были, в связи с чем указанная информация была взята из Атласа по терминальной стадии ХБП: система сбора и анализа нефрологической базы данных США (USRDS 2011). Данные о частоте развития осложнений ЗПТ (перитонит, сепсис) были обнаружены в зарубежных работах Orlando L. A. et al., Ai-Hua Zhang et al. и Lai Seong Hooi et al. Затраты на лечение анемии при ХБП были рассчитаны по наиболее часто используемой схеме и составили 266153 руб. на ГД, 60269 руб. на ПД. Стоимость лечения ВГПТ определялась как сумма затрат на его стандартную фрармакотерапию, включающую в себя препараты витамина Д и фосфоросвязывающие ЛС и фармакотерапию, возникающих на его фроне осложнений, что составила 43259 руб. на ГД, 40527 руб. на ПД. Расчет стоимости лечения осложнений со стороны ССЗ производили на основе соответствующих стандартов медицинской помощи.

Общая стоимость лечения осложнений со стороны ССЗ, с учетом показателей частоты госпитализаций по причине ССЗ на ПД и ГД составили 1 238330 руб. на ГД и 1005561 руб. на ПД. Затраты на лечение перитонита и сепсиса были взяты из тарифов территориального фонда обязательного медицинского страхования. При расчете учитывая частоту возникновений данных осложнений, получили следующие значения: 9237 руб. требуется на лечение перитонита при использовании ПД, на терапию сепсиса на фоне ГД и ПД требуется 9470 руб. 2350 руб., соответственно.

Заключение: Исходя из вышеизложенных результатов анализа затрат на коррекцию осложнений, возникающих на фоне ХБП, наибольших затрат требовали осложнения связанные с ССЗ как на схеме лечения с использованием ГД, так и ПД. Представленные рассчитанные данные анализа затрат на лечение осложнений 3ПТ характеризовались наименьшими значениями как для ГД, так и ПД, среди всех представленных выше составляющих прямых затрат. 